\title{
Educación y pueblos indígenas de Brasil y Colombia: algunas reflexiones a partir de la historia
}

\section{Education and native communities from Brazil and Colombia: some reflections from the history}

\author{
Olga Lucía Reyes*
}

Jaime José Zitkoski*

\section{Resumen}

\begin{abstract}
Este artículo es en un aporte reflexivo para comprender el proceso histórico en el que surgen las propuestas educativas indígenas contemporáneas en Colombia y Brasil. Sabemos que los procesos históricos de estos pueblos son heterogéneos y complejos, no obstante, interesa mostrar algunos aspectos centrales de tres periodos históricos: colonia, inicios de la república y actualidad, en relación al surgimiento e implementación de propuestas educativas. El objetivo es poner en evidencia cómo la educación ha cumplido diversos papeles políticos en relación a los procesos vividos por los pueblos originarios. La conclusión a la que llegamos es que la educación occidental en contextos indígenas ha sido asumida, dinamizada, re-significada y redimensionada de acuerdo con las búsquedas de cada pueblo, para constituirse en parte fundante de sus luchas sociales, culturales y políticas.
\end{abstract}

Palabras clave: Comunidades indígenas. Educación. Historia. Lucha. Organización.

\section{Abstract}

This document it's a reflexive contribution to understand the historical process where the educational indigenous contemporary proposes has emerged in Colombia and Brazil. We know that the historical processes of these communities are heterogeneous and complexes, nevertheless, it's our interest to show some central aspects of three historical periods: Colony, start of the republic period and actuality, in relation with the arise and implementation of educational offers. The objective is to put in evidence how the education have fulfilled several political roles in connection with some processes of the native communities. The conclusion is that the occidental education in native contexts it has been assumed, revitalized, re-meant, and re-measured in agreement with the searches of each community, to be constituted into the central point of the social, cultural and political fights.

Keywords: Native communities. Education. History. Fight. Organisation.

Recebido em: 30/06/2016 - Aprovado em: 24/11/2016

http://dx.doi.org/10.5335/rep.v24i1.7000

Professora na Universidad Pedagógica Nacional de Colômbia e na Universidad de la Sabana. Doutoranda em Educação na Universidade Federal do Rio Grande do Sul. E-mail: olgalureyes@yahoo.com

** Professor do Departamento de Estudos Básicos na Faculdade de Educação da Universidade Federal do Rio Grande do Sul, atuando nos cursos de licenciaturas na área de Filosofia da Educação e no Programa de Pós-Graduação em Educação. Doutor em Educação pela Universidade Federal do Rio Grande do Sul, com pós-doutoramento na Universidade do Estado do Rio de Janeiro. E-mail: 00086365@ufrgs.br 


\section{Introducción}

Para comprender cómo se proyectan las comunidades indígenas hoy en día en relación a la educación, es importante revisar las formas en que se han venido construyendo las relaciones entre las comunidades indígenas con las prácticas educativas no indígenas. En este artículo, antes que hacer un paralelo en las trayectorias de las luchas indígenas de ambos países, -que sería una labor muy ambiciosa-, se busca hacer un acercamiento comprensivo a lo que han sido los caminos recorridos por los pueblos originarios de Colombia y Brasil, en el proceso de construir sistemas educativos propios. Se quiere aportar en el ejercicio de visibilizar y reflexionar críticamente sobre las formas de exclusión y violencia de las que han sido blanco las comunidades a partir de los procesos educativos y poner en evidencia los caminos de luchas y resistencia que han encontrado en estos mismos escenarios.

Con este fin, iniciaremos haciendo un breve recorrido por cómo se relacionaba la colonia y luego la república con los pueblos indígenas, momentos en los cuales, las prácticas educativas impuestas por los colonizadores, en el mejor de los casos, son usadas como formas de control y aculturación de las comunidades indígenas. En estos períodos de la historia, el propósito central era la asimilación e integración o en algunos casos, el exterminio de los indígenas mediante la inserción en las formas de vida implantadas por la colonia y acogidas por las nacientes repúblicas como modelos de vida a seguir.

Luego de esto, basados en las investigaciones de José Bengoa, introduciremos la idea de la emergencia indígena y lo que eso va a significar en términos de reivindicación de la lucha de los pueblos originarios. Finalmente, a partir de dos experiencias concretas, -en el caso colombiano el Consejo Nacional Indígena del Cauca (CRIC) y en el caso de Brasil, las experiencias de las comunidades Guaraní de Rio Grande Del Sur-, intentamos mostrar las formas en que la educación se inserta actualmente en los proyectos políticos de algunos pueblos indígenas de ambos países, como elementos de lucha cultural y política. Finalmente, se plantean algunas reflexiones de cierre.

\section{Los indígenas en Brasil y Colombia: colonia y república}

En este apartado retomaremos brevemente algunos aspectos en torno a cómo se vivió la historia de los pueblos indígenas en relación a los años finales de la colonia y los primeros de la república. Se busca poner en evidencia las formas en que los procesos educativos surgidos en estos momentos, se constituía bajo la 
identidad de campañas "civilizatorias" a partir de las cuales, tanto en Brasil como en Colombia, se intentaba hacer de los indígenas, sujetos integrados, adaptados y útiles para al sistema productivo, en últimas, se gesta un exterminio físico y cultural de los pueblos ancestrales. Enrique Dussel se refiere a los procesos de violencia experimentados por los pueblos originarios en el prefacio de su libro 1492: o encobrimento do outro, en el cual denuncia las crueldades practicadas contra los indígenas por la llamada "civilización moderna", implantada por España y Portugal en América Latina. Él describe de la siguiente forma el proceso de invasión y conquista por las armas en nuestro continente:

Assim também aconteceu com os índios, habitantes do 'novo mundo descoberto': alianças e tratados não cumpridos, eliminação das elites dos povos conquistados, torturas sem fim, exigências de trair sua religião e sua cultura sob pena de morte ou expulsão, ocupação de terras, divisão dos habitantes entre os capitães cristãos da reconquista. O método violento foi praticado durante séculos aqui [...]. A violência iniciou [...] seu longo caminho destrutivo (2000, p. 9).

En Brasil durante la colonia, los indígenas fueron vistos por los portugueses como bárbaros, mano de obra esclavizada y como un problema a controlar a través de procesos de exterminio o de prácticas de asimilación que pasaban por la transformación del indígena en trabajador campesino, hablante de portugués y católico. Bajo estos fines de control y dominación, las comunidades fueron dividas en dos grandes grupos: los tupís que vivían en la costa atlántica y los tapuyas, que eran los habitantes del interior. No obstante, lo fundamental en la colonia era distinguir los indios "mansos", asociados con los tupis, de los indios "bravos" o tapuyas, pues en palabras de Álvarez: "A los llamados tupís se buscaba civilizarlos y convertirlos al catolicismo; mientras que a los tapuyas, se les podría combatir, matar y esclavizar" (2012, p. 25).

Las misiones Jesuitas que iniciaron en Brasil a partir del siglo XVI y se extendieron hasta mediados del siglo XVIII, tuvieron un importante papel en el proceso de pacificación y catequización de las comunidades indígenas. Las misiones tenían como principal estrategia el aldeamiento de los indígenas. Con la ubicación de las comunidades dentro de un territorio delimitado, los religiosos lograban, entre otras cosas, aprender la lengua ancestral, lo que facilitaba la transmisión de valores culturales y religiosos a los pueblos originarios. Dentro de este mismo proceso, la creación de colegios jesuitas al interior de las aldeas, se constituyó en una herramienta efectiva para catequizar y enseñar la lengua portuguesa (OLIVEIRA; DA ROCHA, 2006). De la conjunción de estos dos elementos (saber la lengua indígena y usarla para la posterior catequización de los indígenas), los 
jesuitas lograban generar sistemas de funcionamiento y organización dentro de las aldeas, basados en los modelos europeos católicos.

En cuanto a los procesos de exterminio, estos vinieron por varios frentes además de la ya evidente colonización cultural. La viruela y la gripe se convirtieron en grandes flagelos para los indígenas que no contaban con un sistema inmunológico adaptado a estas enfermedades, por lo cual, se registran en varias crónicas de la colonia, muertes multitudinarias de indígenas contagiados. Por otra parte, también tuvieron lugar las Guerras Justas, mecanismos de guerra adaptados de la edad media y que se utilizaron durante la colonia para justificar la guerra contra las comunidades indígenas que no querían ser catequizadas. Durante las primeras dos décadas del siglo XIX, fue el mismo gobierno colonial quien permitió y legitimo las guerras contra los indígenas. $\mathrm{Al}$ respecto menciona Álvarez que:

[...] a pesar de que [...] fueron aprobadas sólo para algunos territorios (primeramente en Minas Gerais-Espírito Santo y São Paulo, y a partir de 1811 en Goiás y Pará), lo cierto es que la falta de expedición de decisiones reales concernientes a los indios (salvo las referidas a combatirlos) tras la derogación del Diretório en 1798, provocó que en todo el Brasil se practicase de facto estas guerras, que de iure sólo se permitían en los citados territorios (2012, p. 41).

Solo hasta 1845 sería reconocida por primera vez la libertad de los indígenas pero esto supeditado a "Regulamento acerca das missões de catequese e civilização dos índios” (ÁLVAREZ, 2012, p. 41). Se consolida así una mirada sobre el indígena como "menor de edad", trabajador rural y ciudadano de segunda clase que requiere de tutela en el ejercicio de sus deberes y derechos, y como sujeto en proceso de volverse brasilero y poblador potencial del imperio de Brasil, solo a partir de la aceptación de esa forma de ciudadanía.

En la época de la república, los indígenas aparecen en la historia brasilera en medio de procesos de lucha por el territorio y los intentos estatales de organizar la distribución de tierras y la agricultura del país. La imagen creciente del indígena en los inicios del siglo XX en la nación lusófona de Latinoamérica es aquella del sujeto que no puede ser responsable de sí mismo y en esa medida, se crea en 1910 "O serviço de proteçãoaosíndios (SPI) e localização de trabalhadores nacionais" que va a hacer parte del "Ministério da agricultura, industria e comercio" (SOUZA LIMA, 1998, p. 156). Estas organizaciones, además de ser formas de control y regulación "más humanizadas" del accionar indígena en el país, se constituyen en las instituciones abanderadas de realizar "[...] o exercício de uma pedagogía do 'progresso' para o campo simultânea à invenção simbólica do atraso em que se encontraria todo o mundo rural no Brasil" (MENDONÇA, 1990, p. 263-417 en SOUZA LIMA, 1998, p. 158). 
El propósito fundamental de este Serviço va a ser el de convertir a los indígenas en trabajadores del campo, productores rurales autosustentables y también fortalecer las campañas civilizadoras del indígena que se componían de aspectos religiosos pero que también se constituían en formas menos violentas de pacificar regiones del Brasil, con el fin de que los ocupantes indígenas, antes que enemigos, se convirtieran en mano de obra que preparan los territorios productivamente, para la posterior ocupación de los blancos. Esta tarea continúa a lo largo de dos décadas en el Brasil y ya en la década del 30 el SPI inicia un nuevo proyecto de nacionalización y "civilización" de los pueblos indígenas, relacionado con convertir ahora a los indígenas en guardias de frontera (SOUZA LIMA, 1998, p. 165). Este nuevo proyecto se centra en hacer que el indígena desarrolle una identificación con la cultura y la nacionalidad brasilera, a tal punto que lo lleve a generar una cierta lealtad a su nación y que defienda el territorio brasilero de posibles incursiones de los países vecinos.

Estas prácticas asimilacionistas e integracionistas del Brasil, reflejan la mirada que se teje sobre el indígena como un sujeto intelectualmente inferior, por razones biológicas y de raza, que debe ser encaminado para que descubra y acepte las ventajas del "desarrollo" vivido por los ciudadanos brasileros. Dicen Oliveira y Da Rocha al respecto que: "Para isso, seriam adotados métodos e técnicas educacionais que controlariam o processo, estabelecendo mecanismos de homogenização e nacionalização dos povos indígenas" (2006, p. 113). Así, la educación propuesta para este momento de la historia de los pueblos originarios del Brasil, además de ser una práctica foránea e impuesta, está orientada a hacer que el indio deje de ser indio y se vuelva un "brasilero".

Las prácticas de poder y control sobre las comunidades indígenas brasileras continúan desenvolviéndose a lo largo de la década de los 40 a 70, con algunas pequeñas variaciones como la creación de la Fundação Nacional do Índio (Funai) en 1967, cuyo papel principal en la historia reciente de Brasil es proteger y promover los derechos de los pueblos indígenas. Gracias al fortalecimiento que se dio en el proceso de reconocer y defender los derechos de los pueblos indígenas, en 1988 se reformó la constitución nacional y se incluyó en ella, un capítulo (capitulo VIII. De Los índios) dedicado a abordar cuestiones concernientes a la temática indígena, no obstante, las condiciones de exclusión y racismo a las que han sido sometidas los pueblos originarios, continúan presentes hoy en día.

En el caso Colombiano, las experiencias vividas por las comunidades indígenas no se encuentran muy distantes de las comunidades brasileras. Es común también en este país la existencia de una imagen del indígena como ser inferior, salvaje e incluso peligroso, que se encuentra recogida en obras como el Carnero, escrita por Juan Rodríguez Freyle, crónica o novela (su género literario aún se encuentra en 
discusión), impresa por primera vez en 1859 pero cuyo tiraje hecho a mano tiene registros desde 1636.

Las pocas políticas creadas en la Ley de Indias, promulgada en 1542, van a poner el papel proteccionista de los indígenas en manos de la iglesia, siendo los clérigos los encargados de evaluar los procesos de convivencia entre Indígenas y Españoles e imponer las penas. Ya en 1680 se aprueba la figura de resguardo vigente hasta hoy, pero con otras connotaciones y posibilidades, que en sus inicios se asemeja a los procesos de "aldeamiento" de los indígenas brasileros y que va a referirse al establecimiento de terrenos más o menos alinderados para la ocupación indígena, cuya finalidad es facilitar el control de la corona española, sobre las acciones y la economía de las poblaciones (MUESES, 2011).

Los procesos de mestizaje en Colombia fueron muy fuertes y si bien se diezmó la población indígena nativa, también surgieron nuevas "razas" y castas sociales. Para 1778 el censo va a demostrar que el territorio colombiano se constituye como eminentemente mestizo, con una población distribuida así: “[...] 46\% eran mestizos (población de raza mezclada), el 26\% blancos, el 20\% indios y el 8\% negros esclavos. [...] Los indígenas habían llegado a ser una minoría en su propia tierra" (CASTILLO, 2006, p. 139-140). La estructura clasificatoria del siglo XVIII en Colombia es tal, que se da lugar a todo un sistema de castas y de diferenciaciones sociales cuyo más mínimo olvido o confusión, se constituye en motivo de profundos y acalorados conflictos que incluso, terminaban en demandas por difamación. Según Castillo:

El orden racial a finales del siglo XVIII de lo que hoy es Colombia puede ser descrito de la siguiente manera: los negros se encuentran en la parte más baja de la estratificación social. A tal punto llega la situación de subordinación del negro que su cruce con blanco es considerado monstruoso. Se le compara con la naturaleza de las mulas, de allí el término mulato. El indio, en una permanente lucha por defender las tierras de resguardo del hambre de tierras de blancos y mestizos, es obligado a pagar tributos y es también clasificado como un ser inferior. Los mestizos, despreciados por los blancos, odian que los comparen con los indígenas y reclaman su calidad como tales para estar exentos del pago de tributos. Así podrían obtener movilidad social y que en el futuro fueran considerados blancos (2006, p. 144).

Para 1887 se firma el Concordato entre la Iglesia Católica y la república de Colombia.En éste se establece de forma permanente que es la iglesia la responsable directa de la tutela, evangelización y control de las comunidades indígenas, dando lugar así a un agresivo proceso de asimilación cultural de las comunidades indígenas, por medio de la educación religiosa. En función de los procesos de "civilización" ejercidos por la iglesia católica, se van a generar clasificaciones para los indígenas similares a las existentes en Brasil, a saber de tres tipos: 1. indios salvajes, 2. en proceso de civilización y 3. Indios organizados en resguardos (MUESES, 2011). 
Por su parte, el siglo XX en Colombia plantea para las comunidades indígenas el incremento de los conflictos por tierras, pues emerge en el país una clase agraria expansionista, que intenta fortalecer su posición social a partir de procesos de colonización y ocupación de nuevas tierras, muchas de ellas bajo la propiedad legal y comunal de los grupos indígenas. La primera mitad de este siglo va a estar marcada por numerosos intentos y acciones legales dirigidas por el gobierno, para disolver los resguardos y promover la ocupación de terrenos baldíos por parte de militares, políticos y favorecedores del Estado, acciones que en últimas, afectaran directamente los territorios colectivos de los indígenas (KALMANOVITZ; LÓPEZ, 2006). Estas políticas se acompañaban de los sonados discursos de desarrollo y catequización de los indígenas, que justificaron incursiones similares en otros países latinoamericanos y por supuesto, también en Brasil.

Sobre 1960 el gobierno Colombiano empieza a crear de nuevo algunas acciones integracionistas de corte indigenista, validando la posibilidad de la propiedad colectiva y el respeto y/o recuperación de los territorios indígenas, y que encontraron su base en la creación de por ejemplo, el Instituto Indigenista de Colombia (1942) y más adelante, la División de Asuntos Indígenas del Ministerio de Gobierno y la vinculación y participación del INCORA en los procesos de toma de decisiones de la división de tierras (MUESES, 2011).

A finales de los años 70 y principios de los 80 en Colombia, empiezan a surgir entidades y organizaciones indígenas como "El Consejo Regional Indígena del Cauca” (CRIC) y la Organización Nacional Indígena de Colombia (ONIC), entidades con amplia participación de intelectuales indígenas que sin duda, tuvieron un importante papel en la visibilización de los problemas afrontados por estos pueblos y su posterior inclusión y reconocimiento en la reforma constitucional de 1991, en la que Colombia pasa a autoproclamarse como un país pluriétnico y multicultural.

Hasta este punto es posible afirmar que en Brasil y Colombia, al igual que en una amplia región latinoamericana, las políticas indigenistas se constituyeron en las banderas de los gobiernos. En palabas de Stavenhagen:

[...] las políticas indigenistas llevadas a cabo por los estados en los años 40 fueron diseñadas para "integrar" o "asimilar" a los indígenas al modelo cultural nacional dominante. Las ideologías nacionalistas hegemónicas del siglo XX se percibieron a sí mismas como naciones sin indígenas, como naciones pertenecientes a la "civilización occidental" o, por lo menos, como "naciones mestizas", que lograron una especie de síntesis cultural entre las raíces europeas y las indígenas (agregándose en algunos casos elementos africanos), pero cuya identidad era de hecho en gran parte una identidad "occidental” (2002, p. 4).

Esta identidad marcadamente occidental, actuó en detrimento de las condiciones de vida de las comunidades indígenas y negras, que pasaron a ser considerados ciudadanos de segundo grado y a sufrir durante décadas, las 
consecuencias de una clara segregación cultural, económica y social. Podemos observar hasta aquí, que si bien en Brasil y Colombia las políticas y las decisiones gubernamentales fueron tomadas en diferentes ritmos y contextos, son comunes las miradas segregacionistas, de exclusión o invisibilización de la diversidad étnica y cultural del proyecto de nación. Cuando la diversidad fue percibida o exaltada, fue bajo intereses económicos, de control y desarrollistas de las naciones.

Las campañas educativas y políticas orientadas a las comunidades indígenas se caracterizaron en estos periodos de la colonia y el nacimiento de la república, por debatirse entre la integración, la asimilación y el exterminio físico y cultural de los pueblos que habitaban los territorios de estos dos países. En medio de estos procesos, las formas educativas impuestas, ya fueran de orden religioso $o$ civilizatorio, tuvieron un papel clave en los procesos de control o "domesticación" de las comunidades. La educación fue un arma usada para pacificar y "civilizar" a los habitantes de estos dos países, invirtiendo un mínimo de fuerza y evitando así, enfrentamientos violentos. La intensión central de estas formas educativas foráneas fue en el mayor de los casos, el hacer de los indígenas, ciudadanos incorporados al sistema productivo, pero especialmente, ocupando los escalones más bajos de la pirámide ocupacional. Si bien se dieron cambios constitucionales importantes en ambos países, el solo reconocimiento de la existencia y presencia de pueblos originarios en Brasil y Colombia, no se han constituido en un avance suficiente en la superación de las condiciones de exclusión y marginalidad que afrontan estos pueblos.

\section{La emergencia indígena en América Latina}

Como se mostró en el apartado anterior, en la historia de América Latina, por muchos siglos fue natural que las comunidades indígenas fueran invisibilizadas dentro de los proyectos de nación, apareciendo solo en procesos de explotación, exclusión, racismo y/o en intentos de integración y asimilación al sistema nacional a partir de proyectos civilizatorios (STAVENHAGEN, 2002).

Según José Bengoa, entre los años treinta a cincuenta del siglo XX, en América Latina fue común que los NO indígenas hablaran en el lugar de los indígenas en los escenarios deliberativos y de toma de decisiones. Más adelante, en los años 60, en muchos de los países latinoamericanos, en un intento de integración de los indígenas al proyecto nacional, estos son tratados como campesinos e intentan ser asimilados por el Estado y sus políticas, generando acciones que desligaban o desconocían las dimensiones culturales e históricas de las comunidades ancestrales. Dice Bengoa que en ésta década en América Latina "Lo nacional recubrió lo étnico" 
(2000, p. 20) intentando argumentar con ello, que el centro de las reformas eran las políticas desarrollistas que pululaban en varios países latinoamericanos y no las singularidades y diversidad de sus pobladores.

No obstante, a partir de los años 50, las Naciones Unidas comienzan a interesarse en las cuestiones indígenas y la Organización Internacional del Trabajo estructuró un informe sobre las condiciones de vida de algunas de las principales comunidades. Incluso se crea en los años 80 en la Comisión de Derechos Humanos de las Naciones Unidas, un grupo de trabajo dedicado a abordar el tema relacionado con los derechos de las comunidades ancestrales.

Esos cambios en la política mundial, sumados al fortalecimiento interno de los pueblos indígenas, permitieron que en las últimas décadas del siglo XX e inicios del XXI, la historia latinoamericana presenciara lo que Bengoa (2000) denominó como la emergencia indígena. Esta categoría refiere propiamente el afloramiento de la cuestión indígena en diversos escenarios políticos, sociales, económicos de las sociedades latinoamericanas, gracias a procesos de fortalecimiento y surgimiento de nuevas fuerzas, intelectuales y liderazgos indígenas que lograron hacerse notar ante el mundo, para comunicar sus denuncias y demandas y que se traducen en movimientos sociales y levantamientos indígenas de diversa índole. Afirma Bengoa que durante la década del 90: "De diverso modo, de acuerdo a las propias características locales, la emergencia indígena ha ocurrido en casi todos los países de América Latina" (2000, p. 23).

La importancia de esta movilización indígena a nivel latinoamericano radica en que los grupos indígenas organizados, van a salir al mundo, van a tomarse las calles y los escenarios públicos latinoamericanos para poner en evidencia su singularidad, denunciar los abusos a los que han sido sometidos a lo largo de siglos y mostrar la importancia histórica y política que tienen, al sobrevivir como culturas que han resistido el claro proceso de exterminio por parte de la Colonia y el Estado. Los movimientos indígenas van a poner en las agendas nacionales la "cuestión indígena" como un asunto relevante y urgente a ser abordado. Dice Bengoa para enfatizar en la importancia de este fenómeno que:

"La cuestión indígena" conlleva la existencia de nuevos actores indígenas, organizaciones étnicas, reuniones y declaraciones de carácter etnicista, acciones de reivindicación, movimientos étnicos y, en fin, un conjunto de demandas en que el carácter indígena aparece como central. Los indígenas han tenido históricamente demandas frente a la sociedad y el gobierno. Sin embargo no siempre esas demandas ponían por delante los aspectos étnicos, esto es, la diferencia existente entre la cultura indígena y la cultura global criolla. Lo que caracteriza la demanda indígena es que combina diversas peticiones de orden económico y material con la exigencia de respeto por la diversidad cultural y con la gestión de la propia especificidad étnica (2000, p. 24-25). 
En el caso Brasilero, y dada su historia de dictadura militar altamente represiva y violenta ante cualquier intento de levantamiento, la emergencia indígena empieza a hacerse más evidente a partir de la Constitución Federal de 1988, en la cual se va a reconocer la multicultural y diversa del país y a los indígenas como parte importante del Estado. Según Cunha:

No fim da década de 1970 multiplicam-se as organizações não governamentais de apoio aos índios, e no início da década de 1980, pela primeira vez, se organiza um movimento indígena de âmbito nacional. Essa mobilização explica as grandes novidades obtidas na Constituição de 1988, que abandona as metas e o jargão assimilacionistas e reconhece os direitos originários dos índios, seus direitos históricos, à posse da terra de que foram os primeiros senhores (2012, p. 22).

Desafortunadamente, el movimiento indígena unificado (União das Nações Indígenas) en Brasil, que surgido en los años 80, no logró prosperar dada la diversidad de pueblos presentes en el territorio nacional y la extensión del país, pero lo que si permitió fue que los indígenas se reconocieran en sus necesidades comunes y continuaran movilizando acciones de visibilización de sus singularidades, al punto de lograr incidir en la Carta Magna.

Hoy en día la lucha de las comunidades indígenas en el Brasil continua exigiendo no sólo su derecho a la tenencia de tierra, cultura y lengua, sino que también, se han fortalecido en el ejercicio de oponerse a la inserción del capitalismo agresivo en todas las esferas de la vida y asumiendo discursos actuales y reivindicativos de nuevas lógicas como la lucha por el cuidado y protección del medio ambiente, la existencia de una ciudadanía indígena, la justicia social y la alteridad (PORTO BORGES, 2005). La Funai sigue siendo la organización estatal abanderada en el proceso de velar por el respeto y cumplimiento de los derechos de los pueblos indígenas y continúan creciendo y fortaleciéndose un importante número de organizaciones indígenas locales.

En Colombia, la emergencia de los pueblos indígenas como movimiento social, se visibiliza con el surgimiento del Consejo Regional Indígena del Cauca (CRIC) en la década del 70, y la Organización Nacional de Indígenas de Colombia en la década del 80; ambas como organizaciones de base indígena, cuyo proceso de lucha y de trabajo conjunto continua vigente hasta el día de hoy. Si bien el CRIC no es la única organización indígena presente en el país, si es la que ha tenido mayor visibilidad a nivel nacional e internacional y ha logrado tener mayor incidencia en los temas indígenas nacionales.

La importante presencia que logran, en la década de los 70 y 80 , los pueblos originarios en el escenario político de Colombia, va a repercutir en que la asamblea constituyente de 1991, no solo exista participación de líderes indígenas, sino que 
además se reconozca al país como una nación pluriétnica y multicultural, y se creen mecanismos legales que entrarán a garantizar la participación de los pueblos indígenas en procesos electorales y en los escenarios de toma de decisiones en el país.

No obstante, los movimientos indígenas colombianos defendiendo causas muy similares a las demandadas por los pueblos brasileros, han tenido que enfrentar además las vicisitudes y embates que se desprenden del conflicto armado en Colombia, cuyo foco central está en las zonas rurales del país, en las que muchas veces, se encuentran ubicados los territorios indígenas. Es decir, además de enfrentar tensiones con empresas multinacionales y con el mismo Estado, por asuntos de territorio, derechos culturales y recursos naturales, los indígenas colombianos se ven abocados a construir un proyecto político y cultural, en medio de un fuego cruzado entre el Estado y los grupos armados al margen de la ley que se encuentran presentes en el territorio nacional. En ese contexto, las demandas de los pueblos indígenas hacia los actores armados son respeto a sus comunidades y territorios y al Estado, protección y garantía de sus condiciones de vida ${ }^{1}$ (OSORIO, 2011).

Ahora bien, en medio de tanta diversidad contextual, uno de los grandes aportes que van a hacer los movimientos indígenas a los procesos de democratización de los países latinoamericanos es justamente la visibilización de su singularidad, de su capacidad de resistencia a siglos de exterminio, y el hecho de que además de las demandas tradicionalmente realizadas por otros movimientos sociales como justicia, salud, derecho a la vida, etc., los movimientos indígenas introducen luchas como el derecho a la autonomía y la autoderminación, el derecho a tener una cultura propia, la defensa y cuidado del medio ambiente y el factor étnico como un elementos fundamental a tener en cuenta en procesos de desarrollo y planeación de un país.

\section{¿Qué papel juega la educación en estos movimientos indígenas?}

Una de las demandas fundamentales en el proceso de autodeterminación de los pueblos indígenas en Brasil y Colombia va a ser el acceso a los procesos educativos y la posibilidad de poder trazar rutas, sentidos y finalidades de dichos procesos, de acuerdo a los proyectos particulares de cada comunidad. Es decir, más que el simple acceso a la educación, lo que muchos de los pueblos indígenas demandan es que sea respetado su derecho a decidir si quieren la presencia de la escuela o no en sus contextos y qué tipo de escuela desean y necesitan construir para ellos.

Según Dos Santos (2013) la educación indígena existe aun antes de la llegadas de los colonos al continente latinoamericano, lo que no existía era la educación en forma de escuela que va a ser el elemento que se introduce con la llegada de 
los Españoles a Colombia y los portugueses al Brasil. No obstante, los pueblos desde tiempos inmemorables poseen sus propias formas de educar a las nuevas generaciones y sus propias prácticas educativas que aportan al proceso de formación de los integrantes más jóvenes de la comunidad.

Ahora bien, la escuela fue, como se mostró en los primeros apartados de este artículo, una herramienta en función de la aculturación de las comunidades originarias. Más que garantizar la circulación de los aprendizajes occidentales entre las comunidades indígenas a través de la escuela en su versión tradicional, lo que se va a hacer es imponer una cultura, en detrimento de la otra, intentando llevar las culturas e identidades indígenas a su extinción.

Con el surgimiento y fortalecimiento de los movimientos y las luchas indígenas en los diferentes países latinoamericanos, los indígenas van a lograr exigir la posibilidad de decidir sobre los fines, los procesos y los medios a través de los cuáles, sus miembros ingresan y tiene contacto con la escuela (VILLA, 2011). En el caso Colombiano, el CRIC incluso va a tomar distancia de la normatividad existente y de la denominación planteada dentro de la ley general de educación Ley 115 de 1994, en la cual se hace referencia a procesos etnoeducativos para referir las formas propias de educar de cada comunidad étnica del país (MINISTERIO DE EDUCACIÓN. Ley 115 de 1995. Capítulo III. Educación para grupos étnicos).

$\mathrm{El}$ argumento del CRIC es que hablar de procesos etnoeducativos en general, es una nueva forma de homogenización que va a tratar de englobar en una gran categoría, un proceso singular, particularizado y que requiere de la impronta exclusiva de cada cultura. Bajo este argumento, el CRIC comienza a denominar la educación que tiene lugar en la escuela indígena como educación propia y los proyectos educativos como Proyectos Educativos Bilingües (PEB).

En este caso, la escuela que siglos atrás se presentó como una herramienta de colonización y homogenización, a través de los procesos de reconstrucción y re significación indígena, va a empezar a ser reconocida como un elemento que tiene un importante papel político en la lucha del movimiento y es el de garantizar que los niños y jóvenes crezcan en contacto con los saberes occidentales, pero fundamentalmente, que afiancen, conozcan y actualicen los saberes ancestrales de su comunidad en función del fortalecimiento de la organización. Al respecto dice el CRIC:

$\mathrm{Al}$ pasar la emergencia más grave ${ }^{2}$ y recuperar el CRIC sus espacios de acción abierta, el $\mathrm{PEB}$, sigue articulado a las luchas prioritarias de la organización.

[...] las primeras escuelas se constituyen en comunidades fuertemente comprometidas con la lucha por la tierra. Y sobre todo, cómo en todo el desarrollo del programa de educación, los aspectos organizativos priman siempre sobre lo estrictamente pedagógico (CRIC, 2004, p. 16). 
Con lo anterior queda claro que en el caso Colombiano y por lo menos en la propuesta política del CRIC, la educación y particularmente la escuela, tienen un papel eminentemente político y organizativo, y su finalidad trasciende el mero ejercicio de alfabetización de los indígenas, para insertarse en procesos de fortalecimiento cultural, actualización de las tradiciones y lucha por los derechos culturales de los pueblos.

Según Dos Santos (2013), el caso Brasilero tiene sus propias particularidades, pues dada la diversidad de los pueblos indígenas y la historia en la que se ha desenvuelto el trasegar indígena en dicho país:

[...] los pueblos indígenas, actualmente, conviven y desarrollan dos experiencias diferentes de educación: educación propia o educación tradicional (MELIÁ, 1999) y educación escolar. Esas experiencias no son competidoras o provocan conflictos. En muchos pueblos se complementan. Diferentemente de la uniformidad y homogeneidad de la escuela, en el ámbito de la educación indígena (tradicional) cada pueblo desarrolla su sistema y propio proceso de educación, de acuerdo con su experiencia histórica, su actual contexto de vivir bien y su perspectiva de futuro (2013, p. 347).

Si bien la escuela indígena Brasilera no tiene una vinculación tan clara y directa con los movimientos indígenas del país, no se puede negar que para algunas de las comunidades, por lo menos del sur del país, se está convirtiendo en una posibilidad para disminuir la brecha cultural, social y política a la que han sido sometidos durante siglos. Según testimonios recogidos por las investigadoras Ana Luisa Teixira y María Bergamaschi (2009) la escuela para el caso de los Mbya Guaraní de Rio Grande Do Sul permite el acceso a una serie de conocimientos, negados por siglos y muy importantes en el proceso de interacción con el contexto mayoritariamente no indígena. Lo anterior se ilustra en el testimonio del cacique Teófilo recogido por estas investigadoras durante su trabajo en la escuela de Cantagalo:

É importante ter estudo, conhecer o sistema do branco e a língua do branco para saber falar, como lidar as coisas do branco, encaminhar nossos pedidos as coisas que queremos entender, nossos projetos. O estudo é bom pra crianças e pro adulto que saberá melhor entender os sistema do branco (TEIXEIRA; BERGAMASCHI, 2009, p. 131).

Como se puede observar, la escuela se presenta para el caso de esta comunidad como un espacio para adquirir conocimientos como la lengua mayoritaria y técnicas como la escritura, que resultan indispensables en los procesos de lucha por su autonomía y autodeterminación. Lo que aparece claro para los pueblos indígenas del Brasil, es que la escuela indígena debe ser necesariamente diferenciada de la del blanco dado que su obligación es responder a procesos interculturales y bilingües que demande cada una de las comunidades y sus contextos. 
En esa perspectiva, es importante retomar el pensamiento de Paulo Freire sobre lo que él considera una educación liberadora, pues se aproxima al ideal desde el cual hablan los pueblos indígenas. La educación liberadora implica autonomía de la escuela y el derecho de todos los pueblos y comunidades de construir de forma ciudadana sus propios procesos educativos surgidos desde su cultura, su propia historia, como afirmación auténtica de su visión de mundo. Según Freire, “[...] uma educação libertadora [...] requer que os homens se sintam sujeitos de seu pensar, discutindo seu pensar, sua própria visão de mundo, manifestada implícita ou explicitamente, nas suas sugestões e nas de seus companheiros" (1993, p. 120).

Lo que podemos concluir de este breve apartado es que la conquista de una escuela diferenciada en el caso brasilero, o del derecho a una educación propia en el caso colombiano, es uno de los triunfos que se devienen del proceso de movilización indígena en Brasil y Colombia; y si bien, la escuela indígena continua siendo el centro de discusiones políticas y pedagógicas dentro de las mismas comunidades y el camino aún se encuentra en construcción, la posibilidad de una escuela basada en procesos de educación indígena, marca una conquista política crucial para los pueblos, pues la educación y así la escuela, pasaron de ser elementos colonizadores a herramientas de lucha y fortalecimiento de las organizaciones y comunidades indígenas.

\section{Algunas ideas de cierre}

Si bien se evidencian contextos históricos y políticos disimiles en los acontecimientos vividos por pueblosindígenas en Brasily Colombia, esincuestionable que en ambos países se vivieron procesos de exclusión, exterminio y racismo para con las comunidades indígenas. Como lo muestra Villa: "La historia es una larga sucesión de eventos en los que el Estado restringe la autodeterminación indígena e instrumenta o impone un modelo de desarrollo que amenaza la existencia de los pueblos indígenas" (2011, p. 63). Estos hechos históricos llevaron a los pueblos indígenas a generar múltiples formas de resistencia que hacen hoy de ellos testigos y sobrevivientes de la barbarie colonizadora.

En los procesos paulatinos de democratización de los Estados Latinoamericanos, fue posible la emergencia de la diversidad indígena en América Latina y su aporte democratizador al contexto político actual, a partir de la lucha y reivindicación de sus demandas, que en gran medida, se constituyen en luchas altamente significativas al visibilizar la existencia de lo diferente, lo propio, y lo singular en un mundo que tiende cada vez más a la homogenización y la globalización.

Los movimientos indígenas van a demostrar además que en efecto, América Latina es un continente diverso, con una importante raíz indígena que aún pervive 
y que se arraiga a su posibilidad de existencia. Las reivindicaciones indígenas se presentan ante el mundo latinoamericano, como una propuesta clara de otras formas organizativas, como una oposición contundente a los procesos desarrollistas y capitalistas, que amenazan con la destrucción del mundo y la naturaleza. En sus demandas, los pueblos originarios van a relevar asuntos como el medio ambiente, el territorio y el derecho a la diferenciación cultural como aspectos que antes no fueron disputados por otros actores. De ahí su importancia como fuerza política e intelectual en el continente y el mundo.

En cuanto a los procesos educativos disputados y construidos hoy en día por los pueblos indígenas, es claro que se convierten en piezas centrales de su movilización, en aras de fortalecer la capacidad organizativa y de lucha de sus integrantes. En el caso colombiano, la escuela indígena surge fuertemente vinculada con los procesos políticos y organizativos de los pueblos indígenas y en el caso de las comunidades Brasileras estudiadas y según las fuentes consultadas, vemos como la escuela se va transformando poco a poco en esa herramienta de acceso, en condiciones de equidad, a un sistema mayoritariamente blanco y que permite alcanzar unos conocimientos y unas técnicas que potencian el desenvolvimiento indígena en los terrenos de luchas por sus derechos.

En ambos casos, lo que logramos percibir luego de esta breve revisión histórica, es que la educación vinculada a las formas escolares, se está constituyendo para los pueblos indígenas en una forma de lucha política y cultura, que les permite garantizar el fortalecimiento y dinamización de su cultura, así como el acceso a escenarios que por siglos fueron vetados para ellos. La clave central para asumir la educación escolarizada como una forma de lucha está en el nivel de autonomía que los pueblos originarios para definir, interpretar y materializar la escuela dentro de sus culturas. Es decir, a mayor autonomía de los pueblos en sus procesos educativos, más potencia logra la escuela dentro de sus movimientos sociales. La lucha por su autodeterminación continua, pero sin duda, se identifica en el panorama grandes conquistas en relación a defensa y derecho a mantener sus diferencias culturales, es decir, a continuar siendo los Otros.

\section{Notas}

1 En el primer semestre de 2016 se da lugar a la firma del Acuerdo de Paz y fin del conflicto armado entre la guerrilla de las FARC y el gobierno del presidente Juan Manuel Santos. Hecho histórico que se interpreta como una esperanza de mejores horizontes, más dignos e igualitarios, para el pueblo colombiano en general.

2 Con esto los autores se refieren a los procesos de lucha por la recuperación de tierras y la autonomía indígena que tuvieron lugar en Colombia de una forma más violenta en las décadas de los 70 y 80 . No obstante, es de aclarar que las luchas hoy en día continúan a lo largo y ancho del territorio y cada vez con un mayor número de actores involucrados y con diversos intereses. 


\section{Referencias}

ÁLVAREZ, Rubén. Entre la asimilación y el exterminio: los indios de Brasil desde el Diretório hasta la abolición de la esclavitud indígena (c. 1750-1845). Universidade Nova de Lisboa; Universidad de Salamanca, 2012. Disponible en: <https://dialnet.unirioja.es/descarga/articulo/4018402.pdf>. Consultado: 22 julio 2015.

BENGOA, José. La emergencia indígena en América Latina. Chile: Fondo de la Cultura Económica, 2000.

CASTILLO, Luis Carlos. El Estado-Nación pluriétnico y multicultural colombiano: la lucha por el territorio en la reimaginación de la nación y la reivindicación de la identidad étnica de negros e indígenas. Memoria para optar al grado de doctor. Universidad Complutense De Madrid Facultad De Ciencias Políticas Y Sociología, Departamento de Ciencia Política y de la Administración III, 2006. Disponible en: <http://biblioteca.ucm.es/tesis/cps/ucm-t28946.pdf>. Consultado: 25 agosto 2016.

CONSEJO REGIONAL INDÍGENA DE CAUCA (CRIC). ¿Qué pasaría si la escuela...? 30 años de construcción de una educación propia. Programa de Educación Bilingüe. Popayán, 2004.

CUNHA, Manuela. Índios no Brasil. História, direitos e cidadania. 2012. Disponible en: <http:// www.companhiadasletras.com.br/trechos/35025.pdf>. Consultado: 25 mayo 2015.

DOS SANTOS, Gersem José. Educación indígena en el país y el derecho de ciudadanía plena. Revista Retratos de la Escuela, Brasília, v. 7, n. 13, p. 345-357, jul./dic. 2013. Disponible en: <http://www.esforce.org.br/index.php/semestral/article/viewFile/335/511>. Consultado: 30 julio 2016.

DUSSEL, Enrique. 1492: o encobrimento do outro. Petrópolis: Vozes, 2000.

FREIRE, Paulo. Pedagogia do oprimido. São Paulo: Paz e Terra, 1993.

KALMANOVITZ, Salomón; LÓPEZ, Enrique. Aspectos de la agricultura colombiana en el siglo XX. Ensayo síntesis del libro La agricultura colombiana en el siglo XX, Fondo de Cultura Económica. Bogotá: 2006. Disponible en: <http://avalon.utadeo.edu.co/comunidades/grupos/ salomonk/ensayos/Aspectos\%20de\%20la\%20agricultura\%20colombiana\%20en\%20el\%20 siglo\%20XX.pdf>. Consultado: 20 julio 2016.

MINISTERIO DE EDUCACIÓN NACIONAL. Gobierno de Colombia. Ley general de Educación 115 de 1994.

MUESES, Carlos Ariel. Estado y Movimientos Indígenas en Colombia. Elementos para una aproximación histórica en Colombia. Revista CCEHS, Multiculturalidad y Movimientos Indígenas en América Latina, n. 3, agosto 2011. Coorporación Chilena de Estudios Históricos. Disponible en: $<$ https://www.academia.edu/1139129/Estado_y_Movimientos_Ind\%C3\%ADgenas_en_Colombia_ elementos_para_una_aproximaci\%C3\%B3n_hist\%C3\%B3rica>. Consultado: 27 julio 2016.

OSORIO, Carlos. El Movimiento Indígena Colombiano: De La Identidad Negativa A La Identidad Positiva. Revista Agora, AGO.USB Medellín-Colombia, v. 11, n. 1, p. 1- 231, enero/ junio 2011. ISSN 1657-8031. 2011. Disponible en: <http://revistas.usb.edu.co/index.php/Agora/ article/view/383/143>. Consultado: 10 mayo 2016. 
PORTO BORGES, Paulo H. O movimento indígena no Brasil: histórico e desafios. Revista Princípios, São Paulo, n. 80, 2005.

OLIVEIRA, João Pacheco de; DA ROCHA, Carlos Augusto. A presença indígena na formação do Brasil. Brasília: Ministério da Educação, Secretaria de Educação Continuada, Alfabetização e Diversidade; Laced/Museu Nacional, 2006.

SOUZA LIMA, Antônio. O governo dos índios soba gestão do SPI. In: CUNHA, Manuela Carneiro da (Org.). História dos índios no Brasil. São Paulo: Schwarcz, 1998. p. 155 -172.

STAVENHAGEN, Rodolfo. Identidad indígena y multiculturalidad en América Latina Araucaria. Revista Iberoamericana de Filosofía, Política y Humanidades, Universidad de Sevilla Sevilla, España, v. 4, n. 7, primer semestre 2002. Disponible en: <http://www.redalyc.org/ pdf/282/28240702.pdf>. Consultado: 10 agosto 2016.

TEIXEIRA, Ana Luísa; BERGAMASCHI, Maria. Educação ameríndia. A dança e a escola Guarani. Santa Cruz do Sul: Edunisc, 2009.

VILLA, Willam. El movimiento social indígena colombiano: entre autonomía y dependencia. Artículo disponible en el libro Movimientos Indígenas en América Latina. Resistencia y nuevo modelos de integración. Copenhague: IWGIA, 2011. (Serie Debates). 